\title{
Developing a Knowledge-Driven Decision Support System for University/College Selection Problem in Kuwait
}

\author{
Suat Kasap, Danah Abbas, Maryam Khajah, and Marwa Ashknani
}

\begin{abstract}
The future of any high school student depends mostly on selecting the right place to study after graduating from high school. Most high school graduates are lost in selecting their right path in Kuwait due to increasing number of university or college alternatives. This paper explains development of a decision support tools that helps high school fresh graduates to choose the best university or college in Kuwait based on their preferences. To choose the right university to apply, there are many decisions that should be taken into considerations. These decisions are related to variety of universities/colleges and the students' preferred criteria. Decisions upon which university should be selected depends on a list of criteria's, this makes the problem is a multiple criteria decision making (MCDM) problem. A Decision Support System (DSS), more specifically, a knowledge-driven DSS is developed to consider this problem. Analytic Hierarchy Process (AHP) is a MCDM process that is chosen to provide alternative solutions for the students based on their several criteria's. Microsoft excel is used in applying AHP, and a Website is built to represent the future business.
\end{abstract}

Index Terms-Analytical hierarchy process, decision support system, multi-criteria decision making, university/college selection problem.

\section{INTRODUCTION}

Nowadays people face different kinds of selection problems such as; selecting the right car, house, phone, and universities. Most of students are faced to the university selection problem after graduating from high school by deciding where to continue their education. In Kuwait, there are many options of universities/colleges, which put the students in confusion, and they start to wonder where to go, which university, or college fits them the most, and how to take into consideration all the fact that will lead them to the

Manuscript received April 3, 2019; revised August 14, 2019.

Suat Kasap is with the Industrial Engineering Department, College of Engineering and Technology, American University of the Middle East, Kuwait (e-mail: suat.kasap@aum.edu.kw).

Danah Abbas was with the Industrial Engineering Department, College of Engineering and Technology, American University of the Middle East, Kuwait. She is now with the Ministry of Higher Education, Administrative Development and Training Department, Kuwait (e-mail: da25ib@hotmail.com).

Maryam Khajah was with the Industrial Engineering Department, College of Engineering and Technology, American University of the Middle East, Kuwait. She is now with Schlumberger Oil Field Company, Kuwait (e-mail: Maryamkhajah@hotmail.com).

Marwa Ashknani was with the Industrial Engineering Department, College of Engineering and Technology, American University of the Middle East, Kuwait. She is now with the Public Authority for Food and Nutrition, The Engineering Department and Quality Control, Kuwait (e-mail: marwahashknani@gmail.com). right decision. In addition, high schools in Kuwait do not have objective about informing or guiding high school students about universities/colleges. So, a lot of student gets lost after graduating from high school since they neither have information about their options nor how to choose between these options. In this paper, high school graduates of Kuwait are guided in taking the right decision under multiple preferred criteria. Looking at the situation form a scientific view; decision making is an information processing task. It is a cognitive task that requires thinking, diagnosing, evaluating, and choosing. This means that making a decision could be done scientifically and based on scientific tools and techniques. When multiple criteria are important to a decision maker, it may be difficult to choose between alternatives. In such a case Thomas Saaty's [1] analytic hierarchy process (AHP) provides a powerful tool that can be used to make decisions in situations involving multiple criteria. The AHP is one of the most known and applied techniques in analyzing the process of making a decision in a scientific way that simplifies the process and make it clear in terms of numbers and weighs given for each alternative. A Decision Support System (DSS) is an information system that supports decision making process in a variety of domains and it is a tool that helps in judgment and decision making. Knowledge-driven DSSs are person or computer that are specially designed for the ability of problem solving to make recommendation to the user.

In this paper, a knowledge-driven DSS is developed in order to help the students choose the right university/college in Kuwait. The DSS consist of multiple alternatives and multiple criteria. In this case, the alternatives are the universities/colleges and the criteria are the things that affect students' choice while choosing a university/college such as family reasons and financial reasons. To guide the high school graduates about the available alternatives and help them in selecting where to continue their education we used AHP as a tool for the decision-making process. This method is a part of the DSS, and it is used because university/college selection problem is a multi-criteria decision-making problem. To solve university/college selection problem, an AHP is implemented using Microsoft Excel. AHP formulas are plugged into Excel and the consistency ratio is calculated. After doing all of that, Excel gives the most proper university/college depending on the student preferences.

\section{BACKGROUND}

Multi-criteria decision making (MCDM) is a method used 
to decide on a certain subject among multiple criteria. MCDM process starts by defining the problem and objectives. Next, the list of alternatives is stated to meet the objectives. After that, the criteria (attributes) are determined in order to measure the performance. Then studies are performed to collect data and evaluate the criteria. After that, a decision matrix is constructed after organizing alternatives based on criteria. Then weights are assigned for each criterion. After that the alternatives are ranked and discussed with experts. Finally, the decision is made with the help of experts to get the MCDM results [2]. The aim behind MCDM is to provide decision makers with a tool that offers an advanced guide in solving a problem with multiple criteria. There are different types of MCDM methods that are used in solving real life problems expertly, and Analytic Hierarchy Process (AHP) is one of them.

The AHP is a type of structured technique to choose between multiple alternatives based on multiple criteria. The technique is developed in the 1970s [3]. Simply saying, when the person has multiple things to choose from, and his decision is based on defined criterion, the AHP model is applicable. The method is widely used in different fields like education, healthcare, quality assessment, customer requirements, business management, etc. It can be used to choose from multiple options, or to rank alternatives, or to allocate resources properly, or to compare between competitors, or to settle a conflict [4]-[14]. The theory behind implementing the AHP in measuring intangible factors that affect the decision-making process is discussed [15]. How the priorities are driven form comparison judgment between multiple factors are shown. In another application by Saaty [16] a detailed description of a job selection process, where criteria of selection were flexibility, opportunity, security, reputation, and salary are illustrated.

The AHP method is well structured, and it has a set of defined steps to be followed. It starts with modelling the decision to be made, the alternatives, and the selection criterion in a hierarchy. Once the hierarchy is ready with the three levels; goal, criteria, alternatives, comparisons are made. The alternatives are compared in pairs against each of the criterion to be prioritized. Numbers are used to conducts the comparisons. The obtained numbers are then processed to obtain relative priorities for each element. These priorities are absolute numbers between zero and one without dimensions. Finally, these priorities are aggregated to generate evaluation metrics for each of the alternatives. Decision is then made based on the results of the study. The number of criteria and alternatives can vary according to the situation. The advantage of the method is that it can be used in multiple situations, and it has a well-defined structure. The complexity of application increases with the increase in number of alternatives and criteria. The general AHP procedure is as shown in the following steps [14]:

1) Identify the problem and understand it.

2) Construct a decision hierarchy structure as shown in Fig. 1.

3) Develop matrices to compare the levels of Fig. 1. For, each element in the criteria level is compared to each alternative in the alternative level. The comparison is made based on Table I [3], in which it has scales the represents the number of times that an element is more important over the other element.

4) Weight each element in the levels based on the comparison in step 3 , in which weights are assigned based on priorities. Then add the weighted values for each element to get the total priority of the element. This step is repeated until each alternatives' total priority is obtained.

5) We check the total weight of each alternative and we choose the highest one.

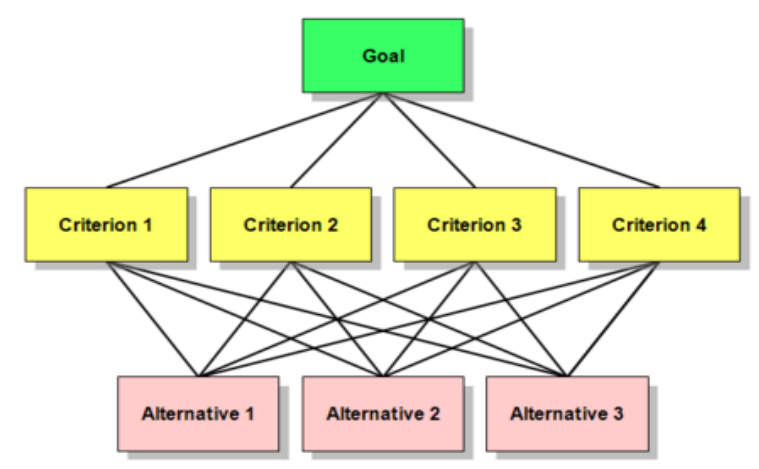

Fig. 1. The decision hierarchy structure for AHP.

TABLE I: SCALES FOR PAIRWISE COMPARISONS

\begin{tabular}{lll}
\hline Scale & Definition & The meaning \\
\hline 1 & Equal importance & Two elements are equally important \\
3 & $\begin{array}{l}\text { Moderate } \\
\text { importance }\end{array}$ & $\begin{array}{l}\text { One element is slightly more } \\
\text { important over another }\end{array}$ \\
5 & $\begin{array}{l}\text { Strong } \\
\text { importance }\end{array}$ & $\begin{array}{l}\text { One element is strongly more } \\
\text { important over another }\end{array}$ \\
7 & Very strong & One element is very strongly more \\
& importance & important over another \\
9 & Extreme & One element is extremely more \\
importance & important over another \\
$2,4,6,8$ & & The intermediate values \\
\hline
\end{tabular}

As mentioned before, there are many researchers that have used AHP to solve for some selection problems [4], [6], [8], [9], [11], [12]. Note that our main focus on university /college selection problem, this problem is also studied by some researchers. A study was made about this issue in Aegean region [17]. This study has found that Students choose their university based on many different criteria. Analytical hierarchy process (AHP) which is a method that helps in multi-criteria decision making was used to help the student choose the right university. Another study used AHP to help making decision in university selection [18]. The study identified the universities, selected the wanted criteria, evaluated universities based on the criteria, and finally choose the best out of them.

Decision support system (DSS) is a computer-based system which help people to take decisions. Both individuals and groups can use DSS, and can be standalone systems, integrated systems, or web-based. They are used when people are facing a complex situation where decision needs to be made. DSS help people to understand the issues of the situation and clarify decisions that are not initially clear or only part of the information is available. DSS can provide the information and the needed structure in order to make a rational decision. In addition, DSS can help decision makers to answer questions in such conditions, for example in business condition; what might happen if the value of a variable changes, how many customers have specific 
characteristics, or any question that an outcome might occur. There are different types of DSSs that include: model-driven systems, data-driven systems, knowledge-driven systems, and group support systems. Model-driven systems use many of financial, optimization, or simulation models as a help to decision making. They use limited data that is provided by decision makers. Data-driven systems use time series data that are gathered on the characteristics of interest at regular intervals over a period of time. For example, in companies, executive support systems are used to determine why the expenses are higher than the expected, be continuously updated on the performance, and check for processes that are not meeting expectations. Knowledge-driven systems are person or computer that are specially designed for the ability of problem solving to make recommendation to the user. They are expert systems that include an application of artificial intelligence to the decision-making process. Last type of DSS is group decision support system, they use network and communication technologies to support decision making. These systems enable workgroups to process and gather information together. Note that, the proposed DSS falls in the category of knowledge-driven DSS.

\section{METHODOLGY}

Kuwaiti students choose their university/college considering many different reasons. In order to find those reasons, a survey was developed and distributed among students in different universities and colleges in Kuwait. The main objective of that survey is to know why each student chose his/her university/college. So, some criteria were listed in the survey and the students were asked to choose the top five criteria that affect their choice when they want to enter a university/college. An option called "other" was also listed in case of the student wanted to write down an extra reason/criterion. To choose the best criteria using a survey that was distributed among 384 students in different universities/colleges in Kuwait. After collecting the surveys, the data were analyzed. The criteria were ranked as a scale from one to five. Number one was treated as the maximum value and number five was treated as the minimum value. The scale was made by assuming $1=100,2=80,3=60,4=40$, and $5=20$. For example, if the student chose a criterion as number 1 , it will be considered as 100 . After summing each criterion, the total numbers were calculated as shown in Table II.

TABLE II: TOTAL VALUES OF EACH CRITERIA

\begin{tabular}{clc}
\hline Number & Criteria & Total value \\
\hline 1 & Education level & 15280 \\
2 & University reputation & 13630 \\
3 & Transportation & 13140 \\
4 & Job opportunity & 14520 \\
5 & Family reasons & 12880 \\
6 & Friends/relationship reasons & 12400 \\
7 & Financial Reason & 9500 \\
8 & University Lifestyle & 14540 \\
9 & Location & 7320 \\
10 & Other & 1660 \\
\hline
\end{tabular}

After sorting the total values, it is decided to choose the top seven criteria to ensure that all students' choices are being considered. The top seven criteria are chosen from Table I and explained in Table III.

TABLE III: CRITERIA FOR UNIVERSITY SELECTION PROBLEM

\begin{tabular}{|c|c|c|}
\hline Symbol & Criteria & Explanation \\
\hline $\mathrm{C} 1$ & Education level & $\begin{array}{l}\text { University has higher worldwide } \\
\text { ranking degree than other } \\
\text { universities. }\end{array}$ \\
\hline $\mathrm{C} 2$ & University lifestyle & $\begin{array}{l}\text { Some students enter a certain } \\
\text { university based on the lifestyle and } \\
\text { the design of the buildings. }\end{array}$ \\
\hline $\mathrm{C} 3$ & Job opportunity & $\begin{array}{l}\text { Some companies tend to hire people } \\
\text { that graduated from a specific } \\
\text { university.so student tend to enter } \\
\text { that university. }\end{array}$ \\
\hline $\mathrm{C} 4$ & University reputation & $\begin{array}{l}\text { People say good or bad things about } \\
\text { the university. }\end{array}$ \\
\hline $\mathrm{C} 5$ & Transportation & $\begin{array}{l}\text { Some students tend to choose } \\
\text { university closer to their home to } \\
\text { minimize transportation distance. }\end{array}$ \\
\hline C6 & Family reasons & $\begin{array}{l}\text { Students enter a certain university } \\
\text { according to their family will. }\end{array}$ \\
\hline $\mathrm{C} 7$ & $\begin{array}{l}\text { Friends/relationship } \\
\text { reasons }\end{array}$ & $\begin{array}{l}\text { Students tend to enter a certain } \\
\text { university to be with their friends. }\end{array}$ \\
\hline
\end{tabular}

In this paper, the goal is to select the most suitable and appropriate university/college from a set of alternative universities and colleges in Kuwait. The criteria were identified by using a survey. The chosen top seven criteria are shown in Table III. The alternatives are available universities/colleges in Kuwait are shown in Table IV.

\begin{tabular}{|c|c|c|c|}
\hline Symbol & Universities in Kuwait & Symbol & Colleges in Kuwait \\
\hline A1 & $\begin{array}{l}\text { American University of } \\
\text { Kuwait (AUK) }\end{array}$ & A8 & $\begin{array}{ll}\text { Algonquin } & \text { College } \\
\text {-Kuwait (AC) } & \end{array}$ \\
\hline A2 & $\begin{array}{l}\text { American University of } \\
\text { the Middle East (AUM) }\end{array}$ & A9 & $\begin{array}{l}\text { American College of the } \\
\text { Middle East (ACM) }\end{array}$ \\
\hline A3 & $\begin{array}{l}\text { Arab Open University } \\
(\mathrm{AOU})\end{array}$ & A 10 & $\begin{array}{l}\text { Australian College of } \\
\text { Kuwait (ACK) }\end{array}$ \\
\hline A4 & $\begin{array}{l}\text { Gulf University for } \\
\text { Science \& Technology } \\
\text { (GUST) }\end{array}$ & A11 & $\begin{array}{l}\text { Box Hill College } \\
\text { Kuwait (BHCK) }\end{array}$ \\
\hline A5 & $\begin{array}{l}\text { Kuwait College of } \\
\text { Science \& Technology } \\
\text { (KCST) }\end{array}$ & A12 & $\begin{array}{l}\text { Kuwait Technical } \\
\text { College }(\mathrm{K}-\mathrm{TECH})\end{array}$ \\
\hline A6 & $\begin{array}{l}\text { Kuwait International } \\
\text { Law School (KILAW) }\end{array}$ & A13 & $\begin{array}{l}\text { The Public Authority for } \\
\text { Applied Education and } \\
\text { Training }\end{array}$ \\
\hline A7 & Kuwait University & & \\
\hline
\end{tabular}

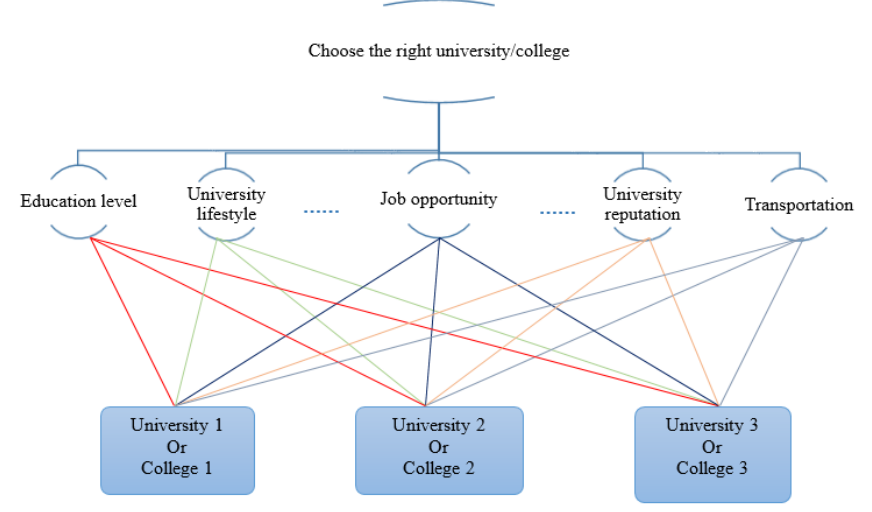

Fig. 2. Decision hierarchy structure of university/college selection problem.

Solving the university/college selection problem by using AHP, a decision hierarchy structure is created as shown in above Fig. 2. Level 1 describes the goal of the analysis which is selecting and choosing the right university or college. Level 2 has the multi-criteria that have several criterions, also 
sub-criteria can be added as shown which are for example transportation, and family reasons. Level 3 is the University/college alternatives from Kuwait. The developed DSS contains the following some basic steps:

1) First step is ranking criteria, developing the ratings for each alternative with each criterion by:

- Making a pairwise comparison matrix of the criteria by using $n x n$ matrix for $n$ criteria. The entry in row $i$ and column $j$ in the matrix shows how much important criteria $i$ is than criteria $j$ based on the preference scale as shown in Table III. After that, ranking of priorities will be developed by considering the equation $A x=\lambda_{\max } * x$ where $\mathrm{A}$ is the $n x n$ matrix we defined above, also called priority matrix, $x$ is the eigenvector, also called priority vector, $\lambda \max$ is the eigenvalue.

- Averaging the value in each row in order to get the corresponding rate, that will construct priority vector for criteria.

- Finally, checking the consistency ratio (CR) to measure how consistent the judgments have been relative to large samples of purely random judgments. AHP provides a method for measuring the degree of consistency among the pairwise comparison that can be provided by the decision maker. If the degree of the consistency is acceptable, the decision process can continue. Otherwise, the decision maker should reconsider and revise the pairwise comparison before proceeding with the analysis. If the $\mathrm{CR}$ is greater than 0.10 , the judgments are inconsistent. $\mathrm{CR}$ can be calculated through $\mathrm{CR}=\mathrm{CI} / \mathrm{RI}$ where $\mathrm{CI}$ is consistency index and RI is the random index. $\mathrm{CI}$ is found by $\mathrm{CI}=(\lambda \max -\mathrm{n}) /(\mathrm{n}-1)$ and RI is the random index. RI depends on the number of elements being compared and takes of the following values given in Table $\mathrm{V}$.

TABLE V: RANDOM INDEX VALUES

\begin{tabular}{ccccccccccc}
\hline $\mathrm{d}$ & 1 & 2 & 3 & 4 & 5 & 6 & 7 & 8 & 9 & 10 \\
\hline $\mathrm{RI}$ & 0 & 0 & 0.5 & 0.9 & 1.1 & 1.2 & 1.3 & 1.4 & 1.4 & 1.5 \\
& & & 8 & 0 & 2 & 4 & 2 & 1 & 5 & 1 \\
\hline
\end{tabular}

2) Second step is ranking alternatives, developing the weights for the alternatives for each criterion by the same steps above. By the end of this step, we will have priority vectors for each alternative.

3) Final step, after finding the priority vectors for each alternative, they should be ranked through summing the product of the criteria times the priority of the decision alternatives so that it will help to choose the one with the highest score.

After knowing how to solve AHP, we applied it using Microsoft Excel. It will take data from the user as an input, solve AHP calculations that was written in Excel, and give the output. To apply AHP to university/college selection problem using Microsoft Excel, the following steps have to be followed.

1) State the main objective: Apply AHP in order to solve university/college selection problem according to student's preferences and derive the priorities among some criteria and alternatives.
2) State the alternatives: The alternatives are the universities and colleges in Kuwait as shown in Table IV.

3) State a number of criteria: Seven criteria as shown in Table III will be selected based on the highest ratings done by the students in different universities/colleges.

4) Form the pairwise comparison matrix: The results of the pairwise comparison matrices will be described in terms of values from 1 which mean equally important to 9 which mean extremely different as shown in Table I. The higher number describes that the chosen factor is more important than another factor that is being compared with. These values represent how likely a person prefers certain criteria upon the other. This will also be applied among the alternatives where the student should use Table I in order to evaluate his/her preferences to a certain university/college upon another university/college among certain criteria.

5) Calculate the weights/scores: First, the pairwise comparison matrix should be normalized by dividing each value in each row by the total number of each column. After normalizing the matrix, the total number of each column should equal to 1 . In addition, the weights should be calculated after normalizing the matrix. Also, the total weights should be normalized so that it should equal to 1 . After that, calculate the overall scores for all alternatives by multiplying the pairwise comparison matrix by the weights calculated above by using matrix multiplication.

6) Checking the consistency: Some pairwise comparison matrices may suffer from inconsistencies. For example, if the student specified that $\mathrm{A} 1$ is more important than $\mathrm{A} 2$, and $\mathrm{A} 2$ is more desirable than $\mathrm{A} 3$, then $\mathrm{A} 1$ should be at lease more desirable than A3 and if the pairwise comparison matrix does not consider this fact, then the matrix suffers from inconsistency.

7) Announcing the most qualified university/college: After checking the consistency, this step will be realized by putting the universities/college and each criterion in a matrix with their weights so that this matrix will be multiplied by the weights of the criteria developed above. After doing this, the most qualified university/college will have the highest score.

\section{Results}

To solve university/college selection problem for high school graduates in Kuwait a website, we have built which is "http://knowyouruniorcollege.wixsite.com/kuwait" in order to spread out solution to university/college selection problem among all high school students. The first page is Home page where we have stated our goal and have a Start button that if one clicks on one will start to fill AHP tables. The place where the student needs to fill the tables is not ready yet because it needs funding to hire programming experts. The process of entering the data by the student is explained through a flowchart shown in the Appendix. The second page is "Information about Universities \& Colleges" which is a page that contain information about each university and college in Kuwait. It contains the majors, phone numbers, email address, address, and website. The third page is "More" 
page which contains "Contact Us" page and "Questionnaire" page.

Developed Knowledge-Driven DSS was tested under different scenarios for the universities where there are five universities as alternatives. Also, it was tested for three universities as alternatives and also three colleges as alternatives. All of these scenarios and their corresponding results are shown below.

For the first case is for student wants to be an engineer. In Kuwait, there are five universities that offer Engineering which are A1, A2, A3, A4, and A5. After filling the pairwise comparison tables and going through AHP, solution was found which is A1. This is shown in Table VI.

\begin{tabular}{|c|c|c|c|c|c|c|c|c|}
\hline & \multicolumn{8}{|c|}{ TABLE VI: AHP SOLUTION FOR THE FIRST CASE } \\
\hline & 0.3 & 0.4 & 0.3 & 0.4 & 0.3 & 0.3 & 0.2 & 0.3 \\
\hline A1 & 1 & 9 & 1 & 1 & 9 & 1 & 8 & 5 \\
\hline & 0.1 & 0.2 & 0.0 & 0.1 & 0.2 & 0.1 & 0.2 & 0.1 \\
\hline A2 & 5 & 1 & 4 & 7 & 5 & 4 & 1 & 7 \\
\hline & 0.0 & 0.1 & 0.2 & 0.0 & 0.1 & 0.1 & 0.2 & 0.1 \\
\hline A3 & 6 & 4 & 0 & 9 & 6 & 1 & 3 & 5 \\
\hline & 0.4 & 0.1 & 0.2 & 0.0 & 0.1 & 0.1 & 0.1 & 0.1 \\
\hline A4 & 0 & 1 & 3 & 3 & 6 & 6 & 6 & 8 \\
\hline & 0.0 & 0.0 & 0.2 & 0.3 & 0.0 & 0.2 & 0.1 & 0.1 \\
\hline A5 & 9 & 5 & 3 & 0 & 3 & 9 & 2 & 5 \\
\hline
\end{tabular}

The second case is for a student specialize in Art. In Kuwait, there are only three universities that offer Art which are $\mathrm{A} 1, \mathrm{~A} 2 \mathrm{t}$, and $\mathrm{A} 3$. After filling the pairwise comparison tables and going through AHP, solution was found which is A2. This is shown in Table VII.

TABLE VII: AHP SOLUTION FOR THE SECOND CASE

\begin{tabular}{rrrrrrrrr} 
& C1 & C2 & \multicolumn{1}{c}{ C3 } & \multicolumn{1}{c}{ C4 } & \multicolumn{1}{c}{ C5 } & C6 & C7 & \\
A1 & 0.2 & 0.1 & 0.2 & 0.4 & 0.1 & 0.2 & 0.1 & 0.2 \\
& 6 & 9 & 4 & 8 & 8 & 1 & 7 & 3 \\
$\mathbf{A 2}$ & 0.6 & 0.7 & 0.5 & 0.4 & 0.6 & 0.1 & 0.7 & 0.6 \\
& 3 & 0 & 5 & 2 & 9 & 3 & 2 & 0 \\
\hline & 0.1 & 0.1 & 0.2 & 0.0 & 0.1 & 0.6 & 0.1 & 0.1 \\
$\mathbf{A 3}$ & 1 & 1 & 1 & 9 & 4 & 6 & 1 & 7
\end{tabular}

The third case is for a student that wants to enter a college and specialize in Art. In Kuwait, there are only three colleges that offer Art which are A1, A2t, and A3. After filling the pairwise comparison tables and going through AHP, solution was found which is A1. This is shown in Table VIII.

TABLE VIII: AHP SOLUTION FOR THE THIRD CASE

$\begin{array}{lllllllll} & \text { C1 } & \text { C2 } & \text { C3 } & \text { C4 } & \text { C5 } & \text { C6 } & \text { C7 } & \\ \text { A1 } & 0.5 & 0.3 & 0.0 & 0.0 & 0.3 & 0.6 & 0.5 & 0.3 \\ & 6 & 7 & 6 & 7 & 4 & 9 & 4 & 8 \\ \text { A2 } & 0.3 & 0.1 & 0.3 & 0.8 & 0.0 & 0.2 & 0.1 & 0.3 \\ & 2 & 4 & 4 & 0 & 7 & 4 & 6 & 1 \\ \text { A3 } & 0.1 & 0.4 & 0.6 & 0.1 & 0.5 & 0.0 & 0.3 & 0.3 \\ & 2 & 9 & 0 & 2 & 9 & 7 & 0 & 1\end{array}$

In the three cases above, solutions were found but for the first case solution cannot be accepted because after checking the all the comparison tables, it showed that one of the tables is not consistent. The consistency ratio needs to be less than or equal to 0.1 which is not in this case. For the other two cases the solution is feasible and can be accepted. So, the problem with AHP is that all the tables need to be consistent in order to have the right solution. This is hard if there are many criteria and alternatives. Technically our problem can be solved using AHP easily because AHP was used before to solve selection problem as mentioned in the literature review.
Also, solutions can be implemented in Microsoft Excel to make it easier to calculate the weights.

\section{DisCUSSION AND CONCLUSION}

Every teenagers' dream is to graduate from high school, but the most important issue comes on deciding the future after high school. Many students have hard time deciding which university/college to choose. So, AHP is used to solve university/college selection problem in Kuwait. The reason for that is that university/college selection problem can easily become multi-criteria problem where there are many alternatives and many criteria. The criteria were chosen depending on a survey that was distributed among students in different universities/colleges in Kuwait. This survey helped us know the most important things that affect students' university/college selection. A DSS was built by applying AHP in Microsoft Excel in order to solve university/college selection problem. Then a website is made to make sure that our solution reaches almost every student around Kuwait.

\section{CONFLICT OF INTEREST}

We declare that this article content has no conflict of interest.

\section{AUTHOR CONTRIBUTIONS}

S. Kasap, D. Abbas, M. Khajah, and M. Ashknani concuted the research; D. Abbas, M. Khajah, and M. Ashknani analyzed the data and wrote the first draft of the research; S. Kasap wrote the final draft of the paper; all authors had approved the final version.

\section{APPENDIX}

The process of entering the data by the student is explained through a flowchart shown in Fig. 3.

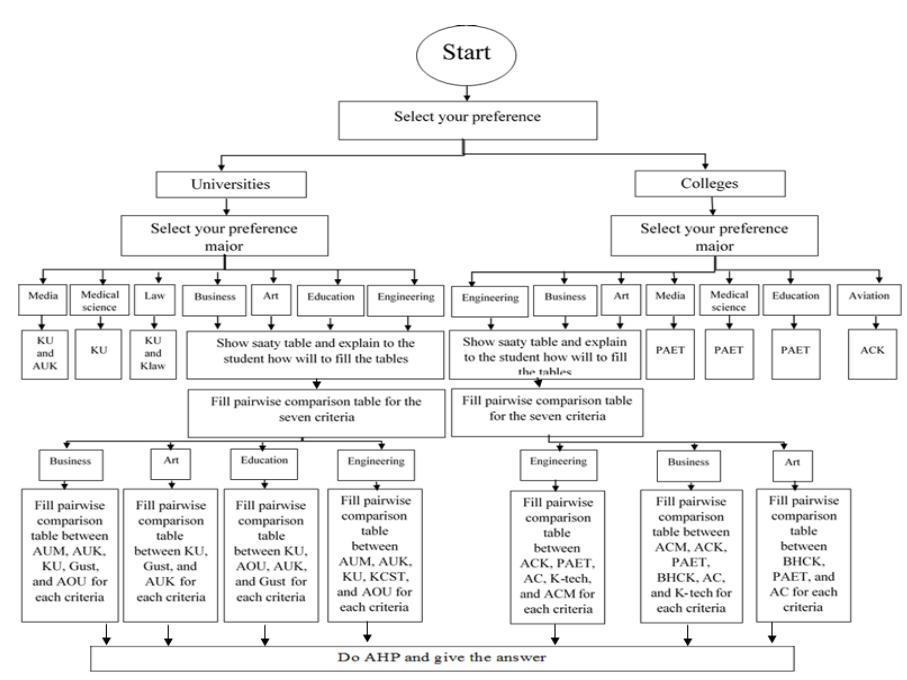

Fig. 3. The process of entering the data flowchart.

\section{REFERENCES}

[1] T. L. Saaty, The Analytical Hierarchical Process, New York: Wiley, 1980.

[2] N. H. Zardari, K. Ahmed, S. M. Shirazi, and Z. B. Yusop, Weighting Methods and Their Effects on Multi-criteria Decision-Making Model 
Outcomes in Water Resources Management, Switzerland: Springer International Publishing AG, 2014, pp. 1-5.

[3] T. L. Saaty, "A scaling method for priorities in hierarchical structures," Journal of Mathematical Psychology, vol. 15, no. 3, pp. 234-281, 1977.

[4] J. Azis, "Analysis Hierarchy Process in the benefit-cost framework: A post-evaluation of the Trans-Sumatra Highway Project," European Journal of Operational Research, vol. 48, no. 1, pp.37-48, 1990.

[5] S. Alidi, "Use of the analytic hierarchy process to measure the initial viability of industrial projects," International Journal of Project Management, vol. 14, no. 4, pp. 205-208, 1996.

[6] O. Bayazit and B. Karpak, "An AHP application in vendor selection," presented at the International Symposium on the Analytic Hierarchy Process (ISAHP) Honolulu, Hawaii, July 8-10, 2005.

[7] A. Ishizakaand and A. Labib, "Analytic hierarchy process and expert choice: Benefits and limitations," OR Insights, vol. 22, no. 4, pp. 201-220, 2009

[8] Y. T. Ic, M. Yurdakul, and E. Eraslan, "Development of a component-based machining centre selection model using AHP," International Journal of Production Research, vol. 50 no. 22, pp. 6489-6498, 2012.

[9] J. Varajao and M. M. Cruz-Cunha, "Using AHP and the IPMA competence baseline in the project managers selection process," International Journal of Production Research, vol. 51, no. 11, pp. 3342-3354, 2013.

[10] D. Garakhani and J. Mehrabi, "Sport marketing outsourcing using SWOT and AHP models," WALIA Journal, special issue 1, pp. 167-171, 2015.

[11] C. M. Tang and M. H. Ngerng, "How do students select social networking sites? An analytic hierarchy process (AHP) model," International Journal of Cyber Society and Education, vol. 8, no. 2, pp. $81-98,2015$.

[12] S. Nallusamy, D. S. L. Kumar, D. K. Balakannan, and P. S. Chakraborty, "MCDM tools application for selection of suppliers in manufacturing industries using AHP, fuzzy logic and ANN," International Journal of Engineering Research in Africa, vol. 19, pp. 130-137, 2016

[13] M. A. Badri, A. Al Qubaisi, J. Mohaidat, H. Al Dhaheri, G. Yang, A. Al Rashedi, and K. Greer, "An analytic hierarchy process for school quality and inspection: Model development and application," International Journal of Educational Management, vol. 30, pp. 437-459, 2016

[14] T. D. Puspitasari, E. O. Sari, P. Destarianto, and H. Y. Riskiawan, "Decision support system for determining scholarship selection using an analytical hierarchy process," Journal of Physics: Conf. Series, vol. 953, p. 12119, 2018.

[15] T. L. Saaty, Principia Mathematica Decernendi: Mathematical Principles of Decision Making, Pittsburgh: RWS Publications, 2009.

[16] T. L. Saaty, "Decision making with the analytic hierarchy process," International Journal of Services Sciences, vol. 1, no. 1, pp. 83-98, 2008.

[17] M. Soba, "Sequence analysis of the university students choice for provinces in the Aegean region using AHP method," Journal of Süleyman Demirel University Institute of Social Sciences, vol. 2, no. 16, pp. 101-115, 2012.

[18] Salimi and J. Rezaei, "Multi-criteria university selection: Formulation and implementation using a fuzzy AHP," Journal of Systems Science and Systems Engineering, vol. 24, no. 3, pp. 293-315, 2015.

Copyright $\odot 2020$ by the authors. This is an open access article distributed under the Creative Commons Attribution License which permits unrestricted use, distribution, and reproduction in any medium, provided the original work is properly cited (CC BY 4.0).

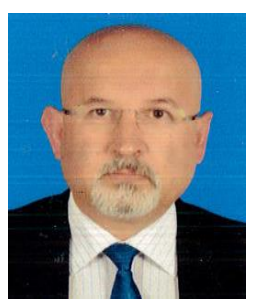

Suat Kasap has degrees in electrical-electronics engineering and industrial engineering. He received his $\mathrm{Ph} . \mathrm{D}$. in industrial engineering from the University of Oklahoma, USA and his B.S. in electrical-electronics engineering from Istanbul Technical University, Turkey. He has M.S. degree in applied mathematics from the University of Central Oklahoma. His major field of study is engineering optimization.
He worked in Industrial Engineering Department of University of Turkish Aeronautics Association, Hacettepe University, and Çankaya University at Turkey. Currently, he is working in Industrial Engineering Department of the American University of Middle East at Kuwait as Associate Professor. He has taught courses on Work Analysis and Design, Ergonomics, Cognitive Ergonomics, Safety Engineering, Technology and Innovation Management, Management of Information Systems, Optimization and Modeling, Operation Research, Project Management, Multi-criteria Decision Making. His research interests are in human factors and ergonomics, occupational safety and health, work and process analysis, technology and innovation management, multi-criteria decision making, financial engineering, data mining, and modeling, analysis, and optimization of complex engineering problems. He published many articles and book chapters.

Dr. Kasap is an active member IEOM society. He and his students won five $1^{\text {st }}$ places and two $2^{\text {nd }}$ places at different international competitions.

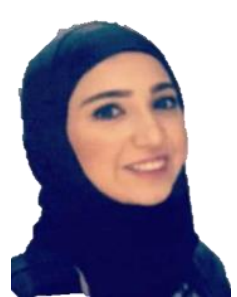

Dana Abbas has degree in industrial engineering. She received her BS in industrial engineering from the American University of the Middle East, Kuwait.

She had a senior project titled as "Developing a Decision Support System for University/College Selection Problem for Kuwait" had been awarded as first place winner for the Senior Design Poster Competition at the 8th International Conference on Industrial Engineering and Operations Management held in Bandung, Indonesia on March 6-8, 2018 with her project teammates. She is also awarded as one of the Kuwaiti Achievers in 2018 regarding all her achievements throughout the year. Currently, she is working in the Ministry of Higher Education in Kuwait as Industrial Engineer in Administrative Development and Training Department.

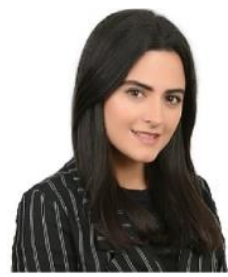

Maryam Khajah has degree in industrial engineering. She received her BS in Industrial Engineering from the American University of the Middle East, Kuwait.

She had a senior project titled as "Developing a Decision Support System for University/College Selection Problem for Kuwait" had been awarded as first place winner for the Senior Design Poster Competition at the 8th International Conference on Industrial Engineering and Operations Management held in Bandung, Indonesia on March 6-8, 2018 with her project teammates. She has done several internships after graduation in Kuwait Institute for Scientific Research, Equate Petrochemical company, Zain Telecommunication company, Babtain Automotive Company, and Schlumberger Oil field company. Each with different roles from dealing with customers, researcher, quality assurance, logistics specialist and Procurement. She is also awarded as one of the Kuwaiti Achievers in 2018 regarding all her achievements throughout the year. Currently working in Schlumberger Oil field company as a material specialist in Material Management.

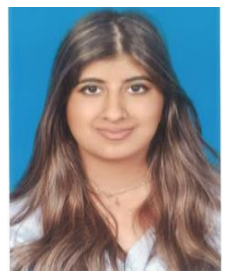

Marwa Ashknani has degree in industrial engineering. She received her BS in industrial engineering from the American University of the Middle East, Kuwait.

She had a senior project titled as "Developing a Decision Support System for University/ College Selection Problem for Kuwait" had been awarded as first place winner for the Senior Design Poster Competition at the 8th International Conference on Industrial Engineering and Operations Management held in Bandung, Indonesia on March 6-8, 2018 with her project teammates. She is also awarded as one of the Kuwaiti Achievers in 2018 regarding all her achievements throughout the year. She worked in the National Fund for SME Development for two months. Currently, she is working in the Public Authority for Food and Nutrition as an industrial engineer in the engineering department and quality control. 